\title{
Einladung zum 11. Impulsgespräch der List Gesellschaft
}

Am 27. September 2011, um 18:00 Uhr, findet das 11. Impulsgespräch der List Gesellschaft e.V. in den Räumlichkeiten der FOM Hochschule für Oekonomie \& Management, Hochschulstudienzentrum Dortmund (Rheinlanddamm 201, 44139 Dortmund), statt.

Bitte merken Sie sich diesen Termin vor und geben Sie ihn gerne auch Interessierten in Ihrem Umfeld bekannt. Der Veranstaltungsablauf ist wie folgt:

\section{BEGRÜBUNG}

Udo Mager

Geschäftsführer der Wirtschaftsförderung Dortmund

Prof. Dr. Karl-Hans Hartwig

Institut für Verkehrswissenschaft, Universität Münster

Schriftführer der List Gesellschaft e.V.

\section{VORTRÄGE \\ „Programmauftrag oder Wettbewerbsverzerrung?}

Die Internetaktivitäten des öffentlich-rechtlichen Rundfunks“

Marc Jan Eumann (MdL)

Staatssekretär bei der Ministerin für

Bundesangelegenheiten, Europa und Medien,

Vorsitzender der Medienkommission beim SPD-Parteivorstand, Berlin

Hendrik Wüst

Geschäftsführer Zeitungsverlegerverband

Nordrhein-Westfalen e.V., Düsseldorf

\section{DisKussion}

Im Anschluss an die Vortragsveranstaltung laden wir zu einem Imbiss ein

Wir bitten um Anmeldung bis zum 20. September 2011 unter mail@list-gesellschaft.de oder unter

Tel.: +49 (0) $201-81004$ 544, Fax: +49 (0) $201-81004399$ 